\title{
Developing Students Verbal Communication Skills and Speech Etiquette in English Language Teaching
}

\author{
Malika Abdikarimova1, Nurzhamal Tashieva1, Aida Tashbolot kyzy' ${ }^{1}$, Zhypargul Abdullaeva ${ }^{2 *}$ \\ ${ }^{1}$ Department of English Phonetics and Grammar, Osh State University, Osh, Kyrgyzstan \\ ${ }^{2}$ Science and Research Department, Osh State University, Osh, Kyrgyzstan \\ Email: *jypar.science@oshsu.kg
}

How to cite this paper: Abdikarimova, M., Tashieva, N., Tashbolot kyzy, A., \& Abdullaeva, Z. (2021). Developing Students Verbal Communication Skills and Speech Etiquette in English Language Teaching. Open Journal of Modern Linguistics, 11, 83-89. https://doi.org/10.4236/ojml.2021.111007

Received: January 6, 2021

Accepted: February 15, 2021

Published: February 18, 2021

Copyright (c) 2021 by author(s) and Scientific Research Publishing Inc. This work is licensed under the Creative Commons Attribution International License (CC BY 4.0).

http://creativecommons.org/licenses/by/4.0/

\begin{abstract}
This article is investigating verbal communication research in teaching the English language, its importance, and necessity in daily human life. The article shows how the teacher should help students to improve and develop their verbal communication skills. For this point, some useful, effective techniques and methods in teaching English language concerning particularly those methods which we have to use for developing students' verbal communication skills are shown and described. The chosen topic is relevant to the fact that verbal communication and speech etiquette have a key place in a person's successful life; therefore many researchers and article readers are interested in this topic. Speech etiquette is a component in the linguistic cultural picture of the world, as well as possessions and understanding of speech etiquette depends on the people behavior. Speech etiquette plays a special role in the foreign language study.
\end{abstract}

\section{Keywords}

English Language, Verbal Communication, Skills, Language Teaching, Speech Etiquette, Learning, Ethics

\section{Introduction}

The relationship between language and its meaning is not straight forward (Sørensen et al., 2019), one reason for this is the complicated limitlessness of modern language semantics, including English (Wali et al., 2017). Language is productive in the sense that there is an infinite number of words and phrases. There is no limit to a language's vocabulary, as new words are introducing daily. Words are 
not the only things we need to communicate, although they are closely related to verbal and nonverbal (Parikh et al., 2014) symbols in terms of how we make the meaning of language. Every symbol represents some meaning related to a certain activity (Zhirenov et al., 2016). Symbols can be used for communication verbally, for example, when spelling the word "winter", in writing it is necessary to put the letters W-I-N-T-E-R together. Communication development is an effective teaching method in improving students technical communication skills as well as empathy (Vogel et al., 2018).

Verbal communication helps express various needs, and in asking questions, that provide us with specific information. Verbal communication is also used in describing things, events, occasions, people, and ideas, by helping people to inform, persuade, and to take into consideration. In other words, verbal expressions help us to communicate with others in explaining our observations, thoughts, feelings, and needs.

Good communication skills are a self-confidence source, enabling a person to exert more control in their life by obtaining knowledge, research effectively, conceptualize, organize, and present ideas and arguments (Emanuel, 2011). Verbal communication skills are a necessary tool for prospering in any subject; even learning these skills will take time, better practices can help students to learn quickly and apply knowledge in work. In addition, with improved communication skills, students will have the confidence and knowledge to not only get a good job but to perform well in interviews (Reith-Hall \& Montgomery, 2019). Communication skills are considered as an ability used to give and receive different kinds of information, similarly, in the development of personality throughout human being existence. During this period, communication becomes essential for personal growth, through which communicating people will find themselves, develop self-confidence, and define the relationship with the surrounding environment. The failure in building good communication skills will happen when people do not want to understand other's opinions, thoughts, ideas, and feelings.

Particularly, there given methods to help students in improving their verbal communication skills and speech etiquette, by the following elements: how to choose words and vocabulary for this or that conversation topic, using key phrases through different dialogues; by watching movies students will be able to understand the language, eye contact, accents; and how to paraphrase and summarize the spoken language, and respond to different types of questions. This article has an actual place in linguistics because important role of verbal communication and speech etiquette in language learning and teaching process. The topic closely connected with methodology, owing to essential methods in teaching verbal communication skills and speech etiquette.

\section{Communication Skills Importance}

For teachers, it is highly important to have enough skills to communicate effec- 
tively, because they considered as one of the necessary determinants in teaching and learning success. In addition to transferring knowledge, the word "educate" is supposed to train learners verbal skills to develop themselves, the impact of higher education, the economy and the broader society transformed along time in various ways (Kromydas, 2017).

In carrying out the learning process, teachers should combine their verbal and nonverbal communication skills; the ability of teachers in applying these types of communication can help improve both, teachers and students impressions in the process of teaching and learning. The teacher is the one who always explains and presents learning material to the class, for this purpose, the teacher should exhibit enough speaking with writing skills. The teacher is required to understand students' verbal communication and be able to help students improve their verbal communication abilities. Verbal communication skills, either they are oral or written; involve vocabulary, mastering skills in choosing the right words to give meaning to the audience. Verbal abilities also concern with skills to organize the words logically.

More importantly, communication is the manifestation of accurate and open attitudes in information change between learners and students. Communication is closely related to culture (Piller, 2007). Nevertheless, the culture itself can be a challenge in building interaction that potentially causes misunderstanding. Language problems can be associated with problems of hearing ability and pronunciation, speed, tone, and tune.

\section{Developing Students Communication Skills}

Participants in this study are teacher and students conducting education process. Students' and teacher's good and adequate communication shows their ethical level in the process of learning and teaching the language. Ethics is one of the most important things, which people need daily everywhere. Here we want to emphasize the regulation of ethical communication in foreign language teaching. Ethics is a branch of philosophy and it has been studied for thousands of years by many researchers.

In communication studies, curricula and ethics are often considered as a central place in service-learning courses, community-engaged activity, and communication activism where students come face-to-face with the harsh realities experienced by society. For some students, it may be the first time they witness and interact with people suffering from lack of basic resources, and sufficient educational opportunities, or subject to environmental hazards, to name just a few persistent inequities. These experiences lend themselves to a rich consideration of communication ethics situated at the individual, organizational, and systemic levels to understand how one voice intersects with others to affirm the dignity of all people as well as promoting learning and competence in everyday communication, as well as social changes through a broad and systemic transformation; ethical communication is necessary for social media, also impacting governmental regulation on ethics (Bowen, 2020). 
Competent and skilled communicators are ethical communicators who take responsibility for a message's creation, impact, and effects in a diverse range of contexts, including mass media, interpersonal, intercultural, professional, and public areas. Stimulating the moral imagination is a key factor that helps students to recognize issues of communication ethics. They learn to weigh their self-interests relative to the self-interest of others, so their communication skills may construct the ethical dimension in the world they live in. In this regard, through the analysis of terminology the term speech etiquette is described in this article. Here we tried to give exact meaning and role of speech etiquette in foreign language learning and teaching.

Speech etiquette is included in the linguistic cultural picture of the world. Possession, understanding and choice of formulas of speech etiquette depends on the people behavior. The choice of speech etiquette formulas is playing a special role in the foreign language study. Without speech etiquette, it is impossible neither to enter the communication, nor to maintain communication, or to complete it. Speech etiquette is a set of requirements to the form, content, order, character and situational relevance of statements adopted in this culture. Speech etiquette, in particular, includes words and expressions used by people to say goodbye, requests, and apologies, accepted in various situations, forms of treatment, intonation features that characterize polite speech, etc. The study of speech etiquette occupies a special position at the junction of linguistics, theory and history of culture, ethnography, country studies, psychology and other humanities (Kereksha, 2019). On the other hand, speech etiquette can be considered from the point of view of language norm. Thus, the idea of correct, cultural, normalized speech includes certain ideas about the norm in the field of speech etiquette (Ushakov, 2008).

\section{Ways to Obtain Good Communication Skills}

There are some characteristics of effective verbal communicators which are very necessary, including active listening, adaptability, adapting one's communication styles to support the situation, clarity, confidence and assertiveness, constructive feedback to giving and receiving it, emotional intelligence for identifying and managing teacher emotions, as well as students emotions, empathy, interpersonal skills as social skills which are especially useful in building strong arguments, interpretation of language, open-mindedness, patience, simplifying the complex, and storytelling.

The way to obtain a good proficiency in verbal communication is mention attributes concerning both the teacher and learners. Essentially, there are a lot of techniques and tools that teacher can use to improve students' verbal communication skills (Figure 1).

The useful thing here is to apply technology such as videos and audios, which are playing the most important role nowadays. Additionally, they will be in interesting and effective sense for students and learners. 


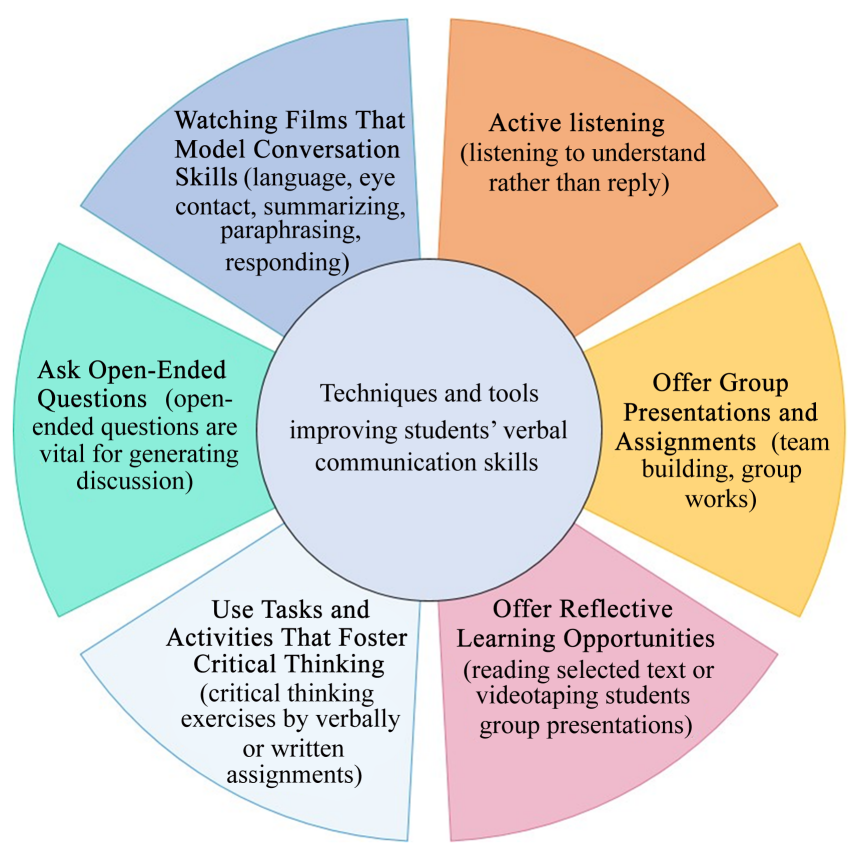

Figure 1. Techniques and tools for improving students' verbal communication skills.

\subsection{Watching Films That Model Conversation Skills}

The conversation is one of the most basic and essential communication skills. It enables people to share thoughts, opinions, ideas, and receive information. Although it may appear simple on the surface, effective conversations include a give-and-take exchange that consists of elements such as language, eye contact, summarizing, paraphrasing, and responding.

Students can learn the fundamental elements of the conversation by watching films or videos about interactions taking place. The teacher can pause the video and ask questions such as, "What message is the listener sending by crossing his arms? What else can you tell by observing the language expressions in the conversation?"

\subsection{Reinforce Active Listening}

Communication is not just about speaking, but also about listening. The teacher can help their students to develop listening skills by reading a selection of text, and then having the class discussion and reflect the content by students explanations. Active listening also means listening to understand rather than a reply. Reinforce building good listening skills by encouraging students to practice asking clarifying questions to fully understand the speakers message.

\subsection{Offer Group Presentations and Assignments}

Team-building exercises can also help students sharpen both oral and written communication skills. Not only does it offer students the chance to work in small groups, thereby reducing some of the pressure, but it also allows them to debate their opinions, take turns, and work together towards a common goal. 


\subsection{Ask Open-Ended Questions}

On the occasion where students require more than a one or two-word response, open-ended questions are vital for inspiring discussion and demonstrating that there are multiple ways to perceive and answer a question. A teacher might set a timer for students informal conversations and challenges to use open-ended questions. For example, teacher can show children the difference in how much more information they can obtain by asking, "What did you like best about the song?" rather than simply "Did you like the song?"

\subsection{Use Tasks and Activities That Foster Critical Thinking}

Another task-based method for improving student communication skills is through critical thinking exercises. These can be done verbally or through written assignments that give students the chance to answer questions creatively using their own words and expressions.

\subsection{Offer Reflective Learning Opportunities}

Recording students reading selected text or videotaping group presentations is an excellent method for assessing their communication strengths and weaknesses. Students can reflect on their oral performance in small groups. Then, ask each student to analyze the others so that they can get used to receiving constructive criticism. Besides these techniques and methods, there are other activities for improving students verbal communication skills, such as role-playing, which showed effective results from previous experiences.

\section{Conclusion}

Effective verbal communication skills include more abilities than just speech. Verbal communication encompasses both how to deliver messages and how to receive. Communication is a necessary skill, which is important to every student, teacher, and person, even to workers, who can convey information clearly and effectively to be highly valued by employers. Employees who can interpret messages and act appropriately on the information they receive have a better chance in their job excellence. Without speech etiquette, it is impossible to join and maintain the communication, or to complete it. Speech etiquette considered as a set of requirements to the certain form, content, order, character and situational relevance of statements adopted in this culture.

\section{Conflicts of Interest}

The authors declare no conflicts of interest regarding the publication of this paper.

\section{References}

Bowen, S. A. (2020). Communication Ethics as a Foundational Construct in Applied Communication Theory, Research, and Practice. In The Handbook of Applied Com- 
munication Research (1015 p.). Hoboken, NJ: Wiley VCH. https://doi.org/10.1002/9781119399926.ch33

Emanuel, R. (2011). Critical Concerns for Oral Communication Education in Alabama and Beyond. Education Research International, 2011, Article ID: 948138. https://doi.org/10.1155/2011/948138

Kereksha, I. A. (2019). Speech Etiquette as a Component of the Cultural Minimum. Young Scientist, 7, 259-260.

Kromydas, T. (2017). Rethinking Higher Education and Its Relationship with Social Inequalities: Past Knowledge, Present State and Future Potential. Palgrave Communications, 3, 1-12. https://doi.org/10.1057/s41599-017-0001-8

Parikh, S. P., Esposito, J. M., \& Searock, J. (2014). The Role of Verbal and Nonverbal Communication in a Two-Person, Cooperative Manipulation Task. Advances in $\mathrm{Hu}$ man-Computer Interaction, 2014, Article ID: 375105. https://doi.org/10.1155/2014/375105

Piller, I. (2007). Linguistics and Intercultural Communication. Language and Linguistics Compass, 1, 208-226. https://doi.org/10.1111/j.1749-818X.2007.00012.x

Reith-Hall, E., \& Montgomery, P. (2019). PROTOCOL: Communication Skills Training for Improving the Communicative Abilities of Student Social Workers: A Systematic Review. Campbell Systematic Reviews, 15, e1038. https://doi.org/10.1002/cl2.1038

Sørensen, M. P., Young, M., \& Pedersen, P. B. (2019). Lost in Transition? On the Migration to English Language Research Publications. In M. Sørensen, L. Geschwind, J. Kekäle, \& R. Pinheiro (Eds.), The Responsible University (pp. 87-114). Cham: Palgrave Macmillan. https://doi.org/10.1007/978-3-030-25646-3 4

Ushakov, D. N. (2008). Big Explanatory Dictionary of the Modern Russian Language (1239 p.). Moscow: Alta-Print House 21sy Century.

Vogel, D., Meyer, M., \& Harendza, S. (2018). Verbal and Non-Verbal Communication Skills Including Empathy during History Taking of Undergraduate Medical Students. BMC Medical Education, 18, 157. https://doi.org/10.1186/s12909-018-1260-9

Wali, W., Gargouri, B., \& Ben Hamadou, A. (2017). Enhancing the Sentence Similarity Measure by Semantic and Syntactico-Semantic Knowledge. Vietnam Journal of Computer Science, 4, 51-60. https://doi.org/10.1007/s40595-016-0080-2

Zhirenov, S. A., Satemirova, D. A., Ibraeva, A. D., \& Tanzharikova, A. V. (2016). The Cognitive Content of the World of Symbols in a Language. International Journal of Environmental Science and Education, 11, 2841-2849. 